\title{
LOAD SHARING ANALYSIS OF PLANETARY GEAR BOX
}

\author{
Sagar B Malkapure ${ }^{1}$, Wadkar S B ${ }^{2}$ \\ ${ }^{I}$ M.E Student, Mechanical, Sinhgad College of Engineering Pune, Maharashtra, India \\ ${ }^{2}$ Professor, Mechanical, Sinhgad College of Engineering Pune, Maharashtra, India
}

\begin{abstract}
One of the advantages of epicyclic transmissions is that the input torque is divided in a number of parallel paths. For $n$ planet epicyclic system, each sun-planet-ring path is to transmit $1 / n$ of the input torque. However, this is only true in the ideal case when there is equal load sharing between all the planets in the epicyclic system. Because of manufacturing errors, equal load sharing is not possible and the degree of inequality in load sharing has major role for gear system sizing, tolerancing schemes, and torque ratings. Therefore it is important to understand the fundamental cause of the unequal load sharing behavior in epicyclic gear sets. Load sharing behavior is associated with positional errors causing one or more planets to lead or lag the other planets. When the error is positive the planet with error lead the other planet while when the error is negative planet with error lags the other planet. Several manufacturing errors can introduce positional errors. Some of the common contributors are carrier pinhole position error, planet size variation, and run out of the gears. A set of precision planetary gear set is selected with the objectives of experimental and theoretical investigation of the load sharing behavior by introducing the position errors for the planets, the load shared by each planet is estimated by maximum stresses induced in each pin. The results of the experimentation are then validated with the FEM (Finite Element method) results.
\end{abstract}

Keywords: Epicyclic gear train, Pinhole position error, Pin stresses, Load sharing

$* * *$

\section{INTRODUCTION}

The epicyclic gear train (EGT) is known as planetary gear train (PGT). Epicyclic gear train is a gearing system consisting of one or more ring gears, or planet gears, revolving about a central, or sun gear. The planet gears are mounted on a movable arm or carrier which itself may rotate relative to the sun gear. Epicyclic gearing systems also incorporate the use of ring gear or annulus, which meshes with the planet gears. Planetary gears are classified as simple and compound planetary gears. Compared to simple planetary gears, compound planetary gears have the advantages of larger reduction ratio, higher torque-to-weight ratio. In many epicyclic gearing systems, one of these three basic components is held stationary; one of the two remaining components is an input, providing power to the system, while the last component is an output, receiving power from the system. The ratio of input rotation to output rotation is dependent upon the number of teeth in each gear, and which component is held stationary. Epicyclic gearing is less expensive, when tooled properly. Epicyclic gear sets are smaller than offset gear sets, having high reduction ratio, high radial loads on output shaft. This makes gear lighter, more compact, more efficient and less noisy. The need of light weight construction and resources results into gearbox designs with high load capacity and power density with high expectations for reliability of the gear. Additional there is a diversity of planetary gears for different application cases. H.Ligata et. al. presented results of a comprehensive experimental and theoretical study to determine the influence of certain key factors in planetary transmissions on gear stresses and planetary load sharing. Pinion position errors are introduced as a representative key manufacturing tolerance, and the resultant changes in the planetary behavior are observed. The experimental data are compared to the predictions of a state-of-the-art multibody contact analysis model - Gear System Analysis Modules (GSAM) [1]. Ajit Bodas et. al. presented a state of the art contact mechanics model of planetary gear set to study the effect of a number of manufacturing and assembly related carrier and gear errors on the load sharing amongst the planets .Three different group of errors are considered: (i) time-invariant, assembly independent errors such as carrier planet pinhole position errors, (ii) time variant, assembly dependent errors such as planet tooth thickness errors, and (iii) time variant, assembly-dependent errors such as gear run out errors[9]. B.Boguski et. al. proposed a new method of measuring planet load sharing of planetary gear sets. The method uses strain gauges mounted directly on the planet pins to measure continuously the loads carried by the planets assembled in a fixed carrier [13].This paper aimed at experimental and theoretical investigation of the load sharing behavior by introducing the position errors for the planets and the load shared by each planet is estimated by maximum stresses induced in each pin. The results of the experimentation are then validated with the Ansys results.

\subsection{Force Distribution in Epicyclic Gear Train}

The force distribution in complete epicyclic gear train is as shown in Fig-1 in which the input torque is applied on the sun gear in clockwise direction causes the sun gear to rotate about its own centre, while planet gears are revolving about the sun gear in anticlockwise direction or vice versa when the ring gear is fixed. The carrier is incorporated to hold the planet gear through pins and produce output of the gear box in anticlockwise direction. 


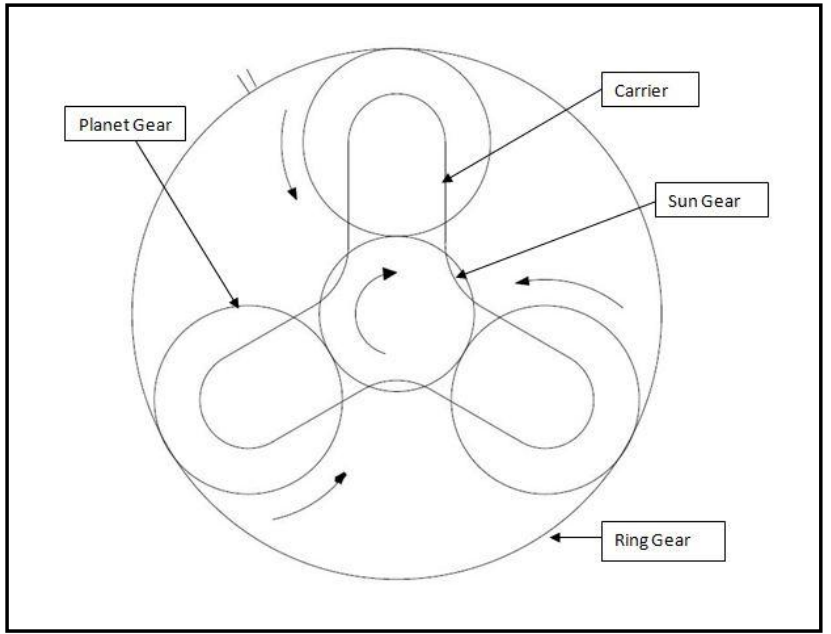

Fig -1: Simple epicyclic gear train

\subsection{Free Body Diagram of Complete Epicyclic Gear}

\section{Train}

Fig- 2 shows the free body diagram of complete epicyclic gear train in which the input torque is applied to the sun gear and this torque is resolve into two component namely tangential force and radial force. In which the tangential force causes bending stresses on the gear tooth and radial force produces the compressive stresses on the gear. The sun gear is engaged to the three planet gears which are at $120^{\circ}$ apart from each other. The planet gear meshes with the sun gear and ring gear which produces two tangential forces, therefore twice the tangential force is require to hold the planet gear.

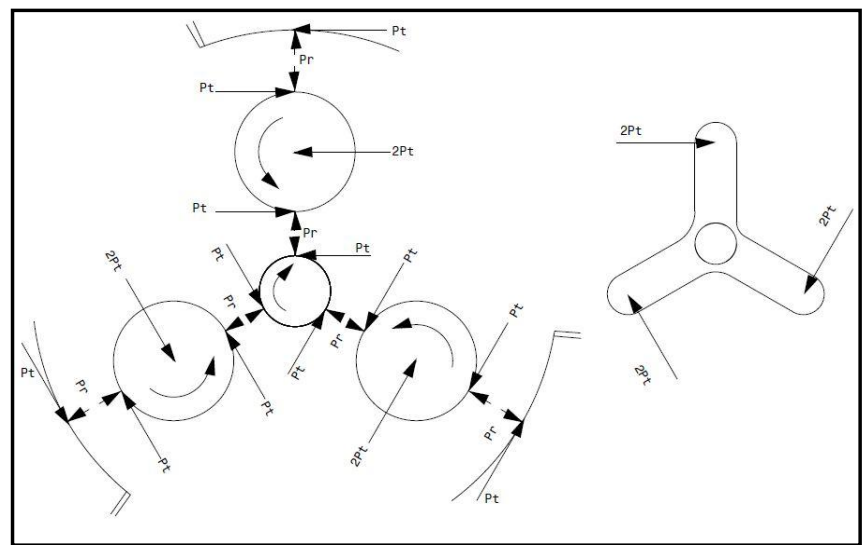

Fig -2: F.B.D of epicyclic gear train

\section{EXPERIMENTAL SETUP}

Epicyclic gear box used for experimentation contains sun gear, three planet gears and a ring gear. The sun gear is input and the carrier is output. The epicyclic gear box is driven by the $2.2 \mathrm{kw}$ motor having maximum $3000 \mathrm{rpm}$. The flexible coupling is used in between output shaft of motor and input shaft of epicyclic gear box. Brake drum dynamometer is attached on the output shaft of epicyclic gear box and two $\mathrm{S}$ type load cells are used to measure torque with a two decimal accuracy. In this one load cell is fixed to the frame and other is attached to the screw for applying tensile force on it. The complete frame is attached to the concrete foundation with the help of foundation bolts to give rigidity and damp the vibration produced by the gear box. This set up was intended to measure the input and output torque. In the present experiment this is not the aim, therefore the system is modified for the static load condition.

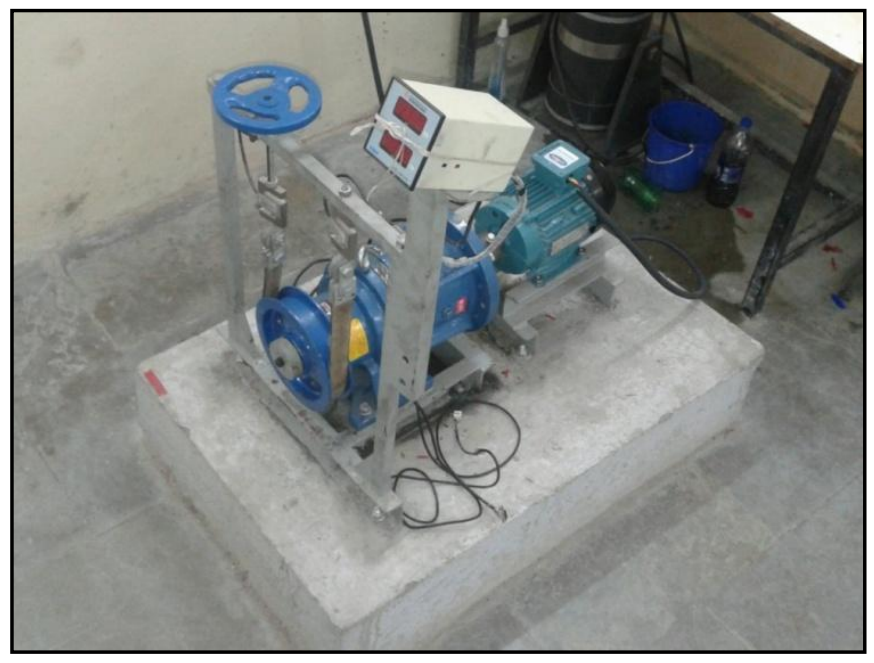

Fig -3: Experimental setup

\subsection{Mounting of Strain Gauge on Pin}

A strain gauge (Micro Measurements BF-350 3AA(11)NoF) is mounted on pins as shown in Fig- 4 to measure strains due to the bending of the pins as a result of the radial loads carried by the planet bearings and planets. Conditioned strain signals from each gauge are converted to stress values and summed to find the total of pin bending stresses such that the percentage represented by a gauge of this total stress value represented the load carried by that planet. Mathematically, the load sharing factor

$$
L S F=\frac{\sigma_{n}}{\sum_{i=1}^{n} \sigma_{n}}
$$

Where, $\sigma=$ individual pin stress

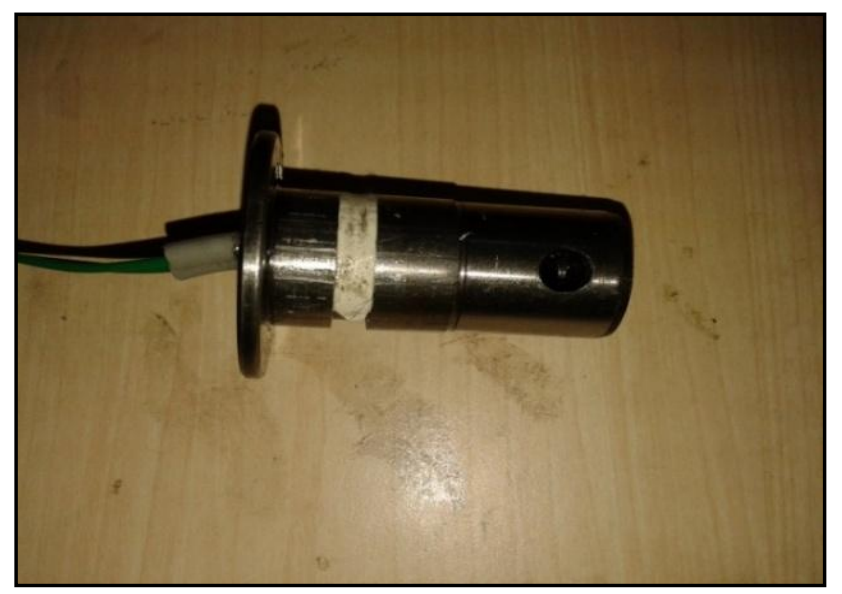

Fig -4: Mounting of strain gauge on pin 


\subsection{Strain Gauge Calibration Setup}

Strain indicators are used to display the voltage difference but in this case strain indicator needs to calibrate to obtain desired output. Strain indicators are calibrated to display the stresses induced in the test specimen. In this case, the strain gauges are mounted on the cantilever beam having rectangular cross section. This cantilever beam is fixed at the one end and the other end is free. The pan is attached on the free end to apply the weight as shown in Fig.6.1.The full bridge circuit is used to increase the accuracy of the experimental results. The calibration is carried out with reference to the theoretical results. As the $1 \mathrm{~kg}$ of load applied on the free end, the theoretical value comes out to be $30.62 \mathrm{~N} / \mathrm{mm}^{2}$, this value is inserted in to strain indicator to replace the voltage difference value. After calibration the strain indicators are used to display stress value irrespective of the test specimen and the applied weight.

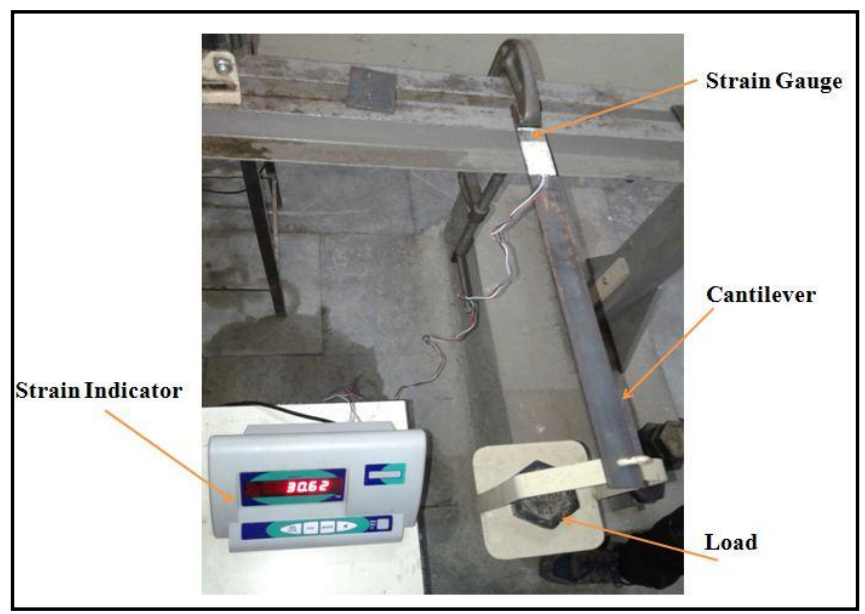

Fig -5: Strain gauge calibration setup

\subsection{Loading Arrangement}

For static analysis, loading arrangement is incorporated to apply the input torque to the sun gear by changing the weight, instead of providing the input torque from the motor. The loading of gear box is made with the help of a lever of $595 \mathrm{~mm}$ in length on one side of which a pan is attached for the purpose of addition of weights, while the other end is having a key slot which can be fitted in the input shaft of the gear box. This results in providing the input torque to the sun gear. Three strain indicators are used to display the strains at three positions of strain gauges on three different pins.

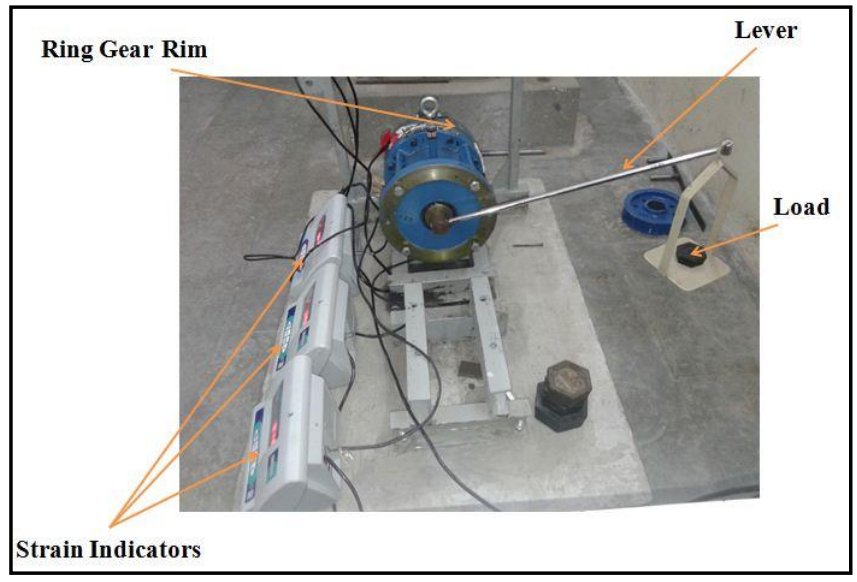

Fig -6: Loading arrangement

\section{PIN STRESS ANALYSIS}

\subsection{Pin Stresses with No Error}

The values of the pin stresses are calculated by using FEM Software as shown in Fig -7. Table -1, Table -2, Table -3 and Table -4 gives the comparison of theoretical values of the pin stresses with the experimental values of the pin stresses and the FEM pin stresses for no error on the pins and percentage load sharing by the pins respectively. The distance between application of force on the lever and center of the shaft is $595 \mathrm{~mm}$.(i.e. a leverage is used to apply the torque to the gears).

Load case 1

Applied torque $=2918.47 \mathrm{~N}-\mathrm{mm}$

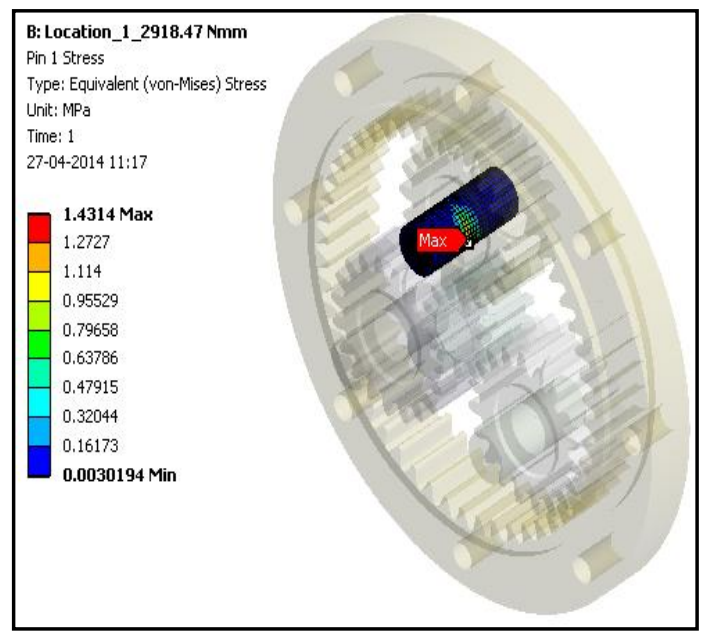

Fig -7: Software results for the pin stress

Table -1: Comparison of Theoretical and Experimental pin stresses

\begin{tabular}{|l|l|l|l|l|}
\hline \multirow{2}{*}{$\begin{array}{l}\text { Applied } \\
\text { Torque } \\
(\mathrm{N}-\mathrm{mm})\end{array}$} & \multirow{2}{*}{$\begin{array}{l}\text { Theoretical } \\
\text { Stress } \\
\left(\mathrm{N} / \mathrm{mm}^{2}\right)\end{array}$} & \multicolumn{3}{|c|}{ Experimental Stress $\left(\mathrm{N} / \mathrm{mm}^{2}\right)$} \\
\cline { 3 - 5 } & Pin 1 & Pin 2 & Pin 3 \\
\hline 2918.47 & 1.439 & 1.38 & 1.23 & 1.44 \\
\hline 5836.95 & 2.878 & 2.90 & 2.73 & 3.02 \\
\hline 8755.42 & 4.317 & 4.55 & 4.17 & 4.70 \\
\hline
\end{tabular}




\begin{tabular}{|l|l|l|l|l|}
\hline & & & & \\
\hline 11673.90 & 5.756 & 5.44 & 5.13 & 5.62 \\
\hline 14592.37 & 7.196 & 7.34 & 7.18 & 7.80 \\
\hline 17510.85 & 8.653 & 8.56 & 8.51 & 8.88 \\
\hline
\end{tabular}

Table -2: Comparison of Theoretical and FEM pin stresses

\begin{tabular}{|l|l|l|l|l|}
\hline \multirow{2}{*}{$\begin{array}{l}\text { Applied } \\
\text { Torque } \\
(\mathrm{N}-\mathrm{mm})\end{array}$} & \multirow{2}{*}{$\begin{array}{l}\text { Theoretical } \\
\text { Stress } \\
\left(\mathrm{N} / \mathrm{mm}^{2}\right)\end{array}$} & \multicolumn{4}{|l|}{ FEM Stress $\left(\mathrm{N} / \mathrm{mm}^{2}\right)$} \\
\cline { 3 - 5 } & 1.439 & 1.43 & 1.33 & 1.55 \\
\hline 2918.47 & Pin 1 & Pin 2 & Pin 3 \\
\hline 5836.95 & 2.878 & 2.86 & 2.67 & 3.11 \\
\hline 8755.42 & 4.317 & 4.29 & 4.29 & 4.66 \\
\hline 11673.90 & 5.756 & 5.72 & 5.72 & 6.22 \\
\hline 14592.37 & 7.196 & 7.15 & 7.15 & 7.77 \\
\hline 17510.85 & 8.653 & 8.88 & 8.58 & 9.33 \\
\hline
\end{tabular}

Table -3: Percentage Load Sharing (Experimental) for different values of Torque

\begin{tabular}{|l|l|l|l|}
\hline \multirow{2}{*}{$\begin{array}{l}\text { Applied } \begin{array}{l}\text { Torque } \\
\mathrm{mm})\end{array} \\
2918.47\end{array}$} & \multicolumn{3}{|l|}{ \% Load Sharing (Experimental) } \\
\cline { 2 - 4 } & Pin 1 & Pin 2 & Pin 3 \\
\hline 5836.95 & 33.53 & 31.56 & 34.91 \\
\hline 8755.42 & 33.90 & 31.07 & 35.02 \\
\hline 11673.90 & 33.60 & 31.69 & 34.71 \\
\hline 14592.37 & 32.89 & 32.17 & 34.95 \\
\hline 17510.85 & 32.99 & 32.79 & 34.22 \\
\hline
\end{tabular}

Table -4: Percentage Load Sharing (F.E.M) for different values of Torque

\begin{tabular}{|l|l|l|l|}
\hline \multirow{2}{*}{$\begin{array}{l}\text { Applied } \\
\text { Torque } \\
\mathrm{mm})\end{array}$} & \multicolumn{3}{|l|}{ \% Load Sharing (F.E.M) } \\
\cline { 2 - 4 } & Pin 1 & Pin 2 & Pin 3 \\
\hline 2918.47 & 33.18 & 30.86 & 35.96 \\
\hline 5836.95 & 33.10 & 30.90 & 36.00 \\
\hline 8755.42 & 33.10 & 30.94 & 35.96 \\
\hline 11673.90 & 33.08 & 30.94 & 35.97 \\
\hline 14592.37 & 33.09 & 30.96 & 35.96 \\
\hline 17510.85 & 33.08 & 30.96 & 35.97 \\
\hline
\end{tabular}

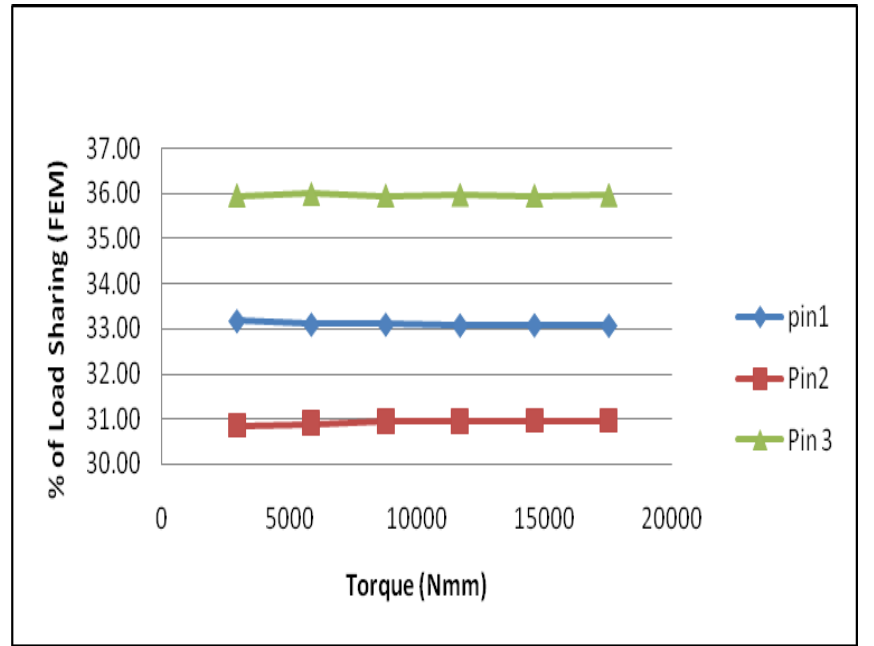

Chart -1: Percentage load sharing by F.E.M Versus Torque

Chart -1 shows the percentage load sharing which is calculated from the results of the pin stresses by finite element method for different values of the torque. Pin 3 shows more load than pin 1 and pin 2. Pin 2 shows minimum load.

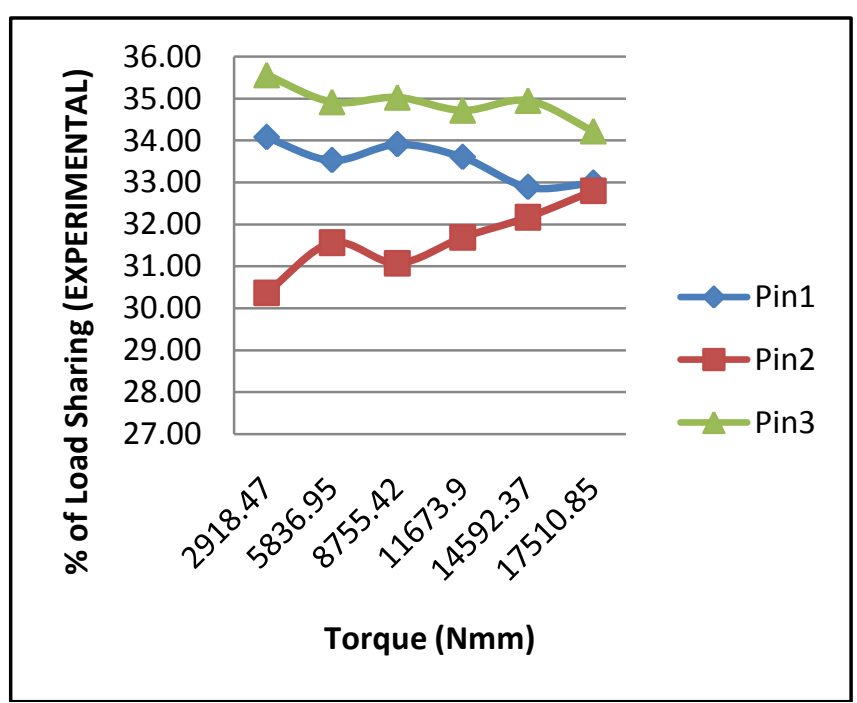

Chart -2: Experimental percentage load sharing Versus Torque

Chart -2 shows the percentage load sharing which is calculated from the results of the pin stresses from experimentation for different values of the torque. Load sharing (L.S) for pin 3 decreases with increasing torque. Pin 2 shows tendency of more load sharing at high torque. Load sharing of pin 1 decrease with high torque.

From Chart -1 and Chart -2 it can be concluded that actual load sharing is different than the theoretical because of manufacturing errors and other parameters. 


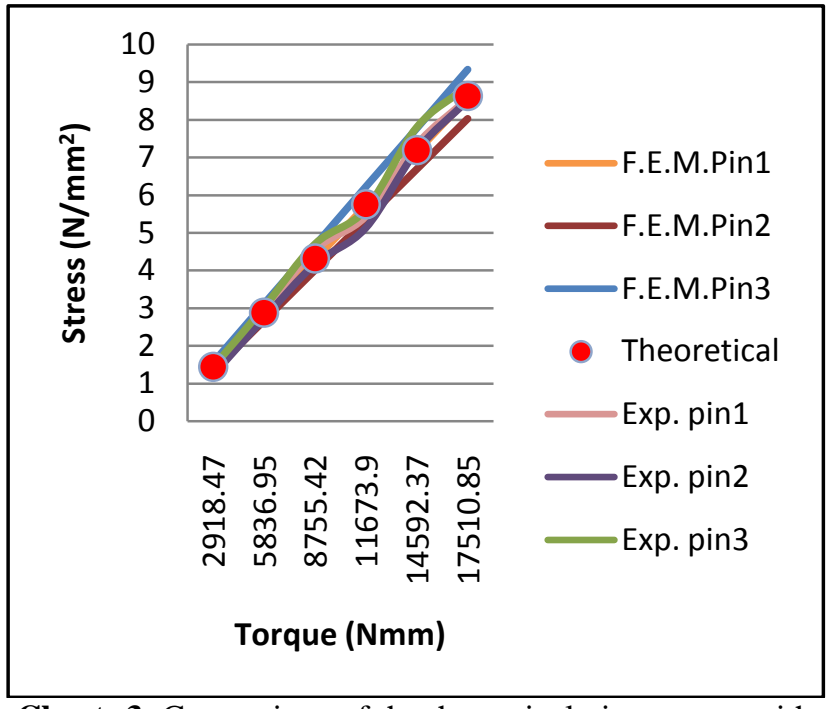

Chart -3: Comparison of the theoretical pin stresses with F.E.M and Experimental pin stresses Versus Torque

Chart -3 shows the comparison of the theoretical pin stresses with F.E.M and experimental pin stresses for the different values of torque. From the figure it is clear that with increase in the torque the pin stress increases. The theoretical and experimental result match closely with the finite element method results

\subsection{Pin Stresses with Error}

Fig -8 shows the maximum value of the von - mises stresses generated in the planet pins when an error of $100 \mu \mathrm{m}$ is provided on the pin 1 for the load case 1 of the Table -5

\section{Load case 1}

Applied torque $=2918.47 \mathrm{~N}-\mathrm{mm}$

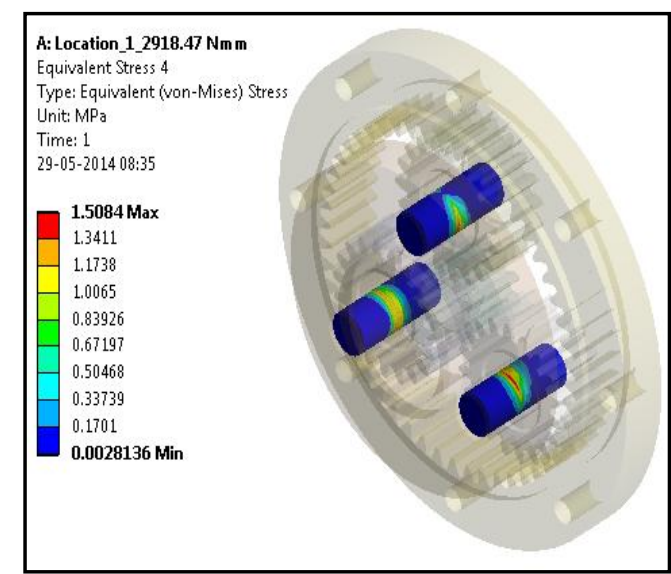

Fig -8: Software results for planet pin 1 for error of $100 \mu \mathrm{m}$

Fig -9 and Fig -10 shows the stresses generated in planet pin 2 and pin 3.

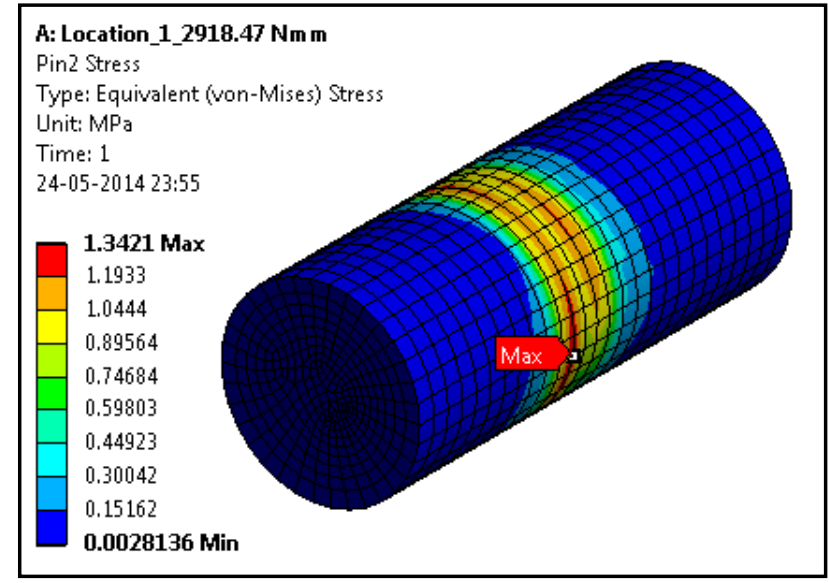

Fig -9: Software results for planet pin 2 for error of $100 \mu \mathrm{m}$

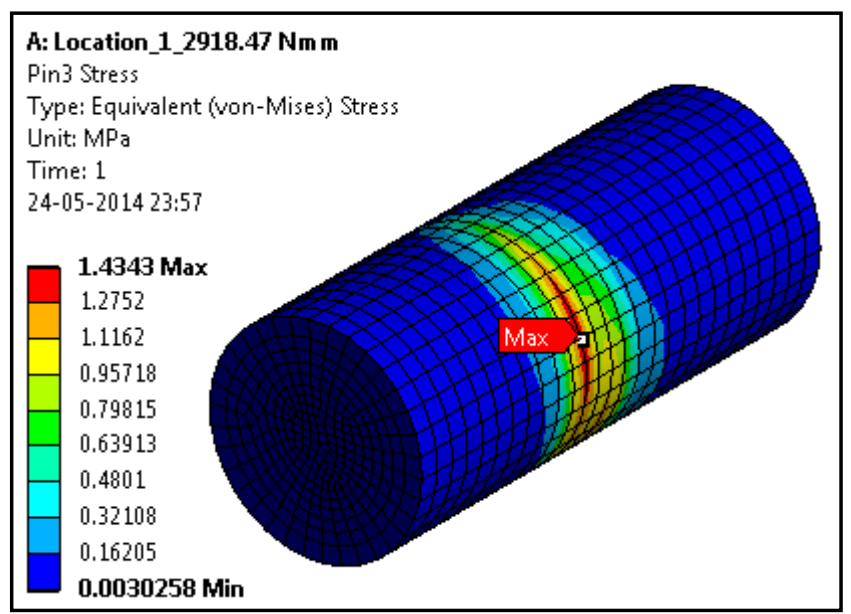

Fig -10: Software results for planet pin 3 for error of $100 \mu \mathrm{m}$

Table -5: Comparison of Theoretical and Experimental pin stresses (with error on pin 1)

\begin{tabular}{|l|l|l|l|l|}
\hline \multirow{2}{*}{$\begin{array}{l}\text { Applied } \\
\text { Torque } \\
(\mathrm{N}-\mathrm{mm})\end{array}$} & \multirow{2}{*}{$\begin{array}{l}\text { Theoretical } \\
\text { Stress } \\
\left(\mathrm{N} / \mathrm{mm}^{2}\right)\end{array}$} & \multicolumn{4}{|c|}{ Experimental Stress $\left(\mathrm{N} / \mathrm{mm}^{2}\right)$} \\
\cline { 3 - 5 } & 1.461 & 1.54 & 1.33 & 1.50 \\
\hline 2918.47 & Pin 1 & Pin 2 & Pin 3 \\
\hline 5836.95 & 2.922 & 3.03 & 2.72 & 2.88 \\
\hline 8755.42 & 4.382 & 4.58 & 4.06 & 4.42 \\
\hline 11673.90 & 5.844 & 6.06 & 5.30 & 5.70 \\
\hline 14592.37 & 7.305 & 7.58 & 6.76 & 7.20 \\
\hline 17510.85 & 8.766 & 9.02 & 8.06 & 8.56 \\
\hline
\end{tabular}

Table -6: Comparison of Theoretical and FEM pin stresses

\begin{tabular}{|l|l|l|l|l|}
\hline \multirow{2}{*}{$\begin{array}{l}\text { Applied } \\
\text { Torque } \\
(\mathrm{N}-\mathrm{mm})\end{array}$} & \multirow{2}{*}{$\begin{array}{l}\text { Theoretical } \\
\text { Stress } \\
\left(\mathrm{N} / \mathrm{mm}^{2}\right)\end{array}$} & \multicolumn{3}{|l|}{ FEM Stress $\left(\mathrm{N} / \mathrm{mm}^{2}\right)$} \\
\cline { 3 - 5 } & Pin 1 & Pin 2 & Pin 3 \\
\hline 2918.47 & 1.461 & 1.50 & 1.34 & 1.43 \\
\hline 5836.95 & 2.922 & 3.01 & 2.68 & 2.86 \\
\hline
\end{tabular}




\begin{tabular}{|l|l|l|l|l|}
\hline 8755.42 & 4.382 & 4.52 & 4.02 & 4.30 \\
\hline 11673.90 & 5.844 & 6.03 & 5.36 & 5.73 \\
\hline 14592.37 & 7.305 & 7.54 & 6.71 & 7.17 \\
\hline 17510.85 & 8.766 & 9.05 & 8.05 & 8.60 \\
\hline
\end{tabular}

Table -7: Percentage Load Sharing (Experimental) for different values of Torque (with error on pin 1)

\begin{tabular}{|l|l|l|l|}
\hline \multirow{2}{*}{$\begin{array}{l}\text { Applied } \\
\text { Torque } \\
\mathrm{mm})\end{array}$} & \multicolumn{3}{|l|}{ \% Load Sharing (Experimental) } \\
\cline { 2 - 4 } & Pin 1 & Pin 2 & Pin 3 \\
\hline 2918.47 & 35.24 & 30.43 & 34.32 \\
\hline 5836.95 & 35.11 & 31.51 & 33.47 \\
\hline 8755.42 & 35.06 & 31.08 & 33.84 \\
\hline 11673.90 & 35.52 & 31.06 & 33.41 \\
\hline 14592.37 & 35.19 & 31.38 & 33.42 \\
\hline 17510.85 & 35.17 & 31.43 & 33.38 \\
\hline
\end{tabular}

Table -8: Percentage Load Sharing (F.E.M) for different values of Torque (with error on pin1)

\begin{tabular}{|l|l|l|l|}
\hline \multirow{2}{*}{$\begin{array}{l}\text { Applied } \\
\text { Torque } \\
\mathrm{mm})\end{array}$} & \multicolumn{3}{|l|}{ \% Load Sharing (F.E.M) } \\
\cline { 2 - 4 } & Pin 1 & Pin 2 & Pin 3 \\
\hline 2918.47 & 35.20 & 31.32 & 33.47 \\
\hline 5836.95 & 35.20 & 31.32 & 33.47 \\
\hline 8755.42 & 35.20 & 31.32 & 33.47 \\
\hline 11673.90 & 35.20 & 31.32 & 33.47 \\
\hline 14592.37 & 35.20 & 31.32 & 33.47 \\
\hline 17510.85 & 35.20 & 31.32 & 33.47 \\
\hline
\end{tabular}

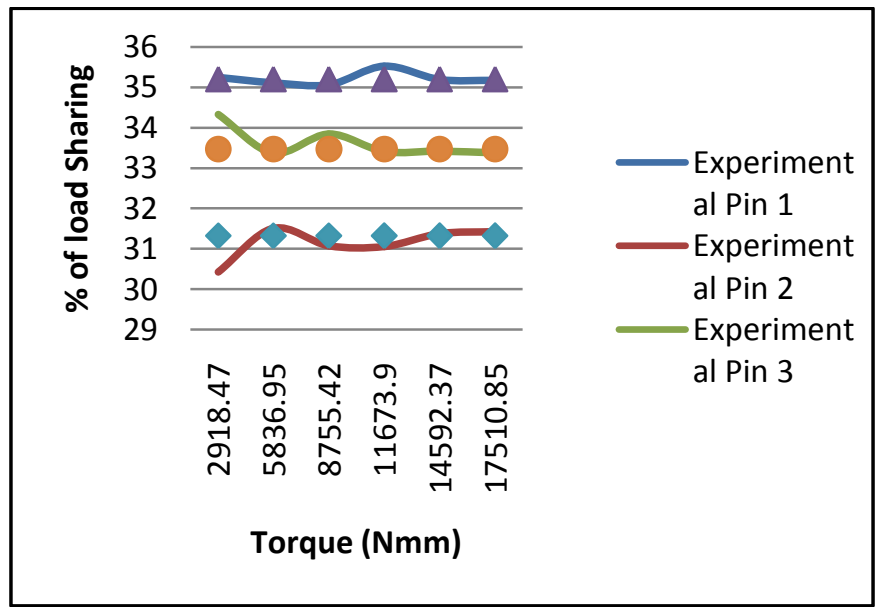

Fig -14: Comparison of the percentage load sharing by experimental results and F.E.M results versus Torque

Chart 4 shows the comparison of the percentage load sharing by experimental results with that of F.E.M results for different values for torque. From the figure it is clear that the pin no.1 (with an error of $100 \mu \mathrm{m}$ ) is highly stressed with the higher percentage of load sharing.

\section{CONCLUSIONS}

- The stresses in the planet pins increases with the increase in the torque.

- Manufacturing errors and planet pin-hole position errors prevents the equal load sharing in the planetary gear box.

- When an error of $100 \mu \mathrm{m}$ is provided on the pin of the planet, the planet pin with error takes the more load as compared to the remaining planets.

- $\quad$ The pin stresses calculated theoretically are in good agreement with experimental results and FEA results.

\section{REFERENCES}

[1]. H.Ligata"Internal Gear Strains and Load Sharing in Planetary Transmissions: Model and Experiments", SAE Paper No. 700178, (1970) pp. 655 - 656.

[2]. A. Singh, "Load sharing behavior in epicyclic gears physical explanation and generalized formulation", Mechanism and Machine Theory 45 (No. 3) (2010) pp. 511 -530 .

[3]. A. Kahraman, "Static Load Sharing Characteristics of Transmission Planetary Gear Sets: Model and Experiment",SAE Paper No. 1999-01 pp. 1050 - 1060.

[4]. A. Bodas, A. Kahraman, "Influence of carrier and gear manufacturing errors on the static load sharing behavior of planetary gear sets", JSME InternationalJournal Series C 47 (2004) pp 908-915.

\section{BIOGRAPHIES}

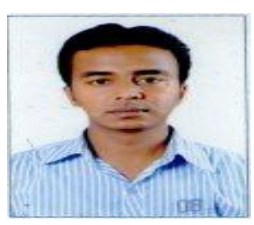

Malkapure Sagar .B Student, M.E Mechanical Design Engineering, Sinhgad College of Engineering, Pune

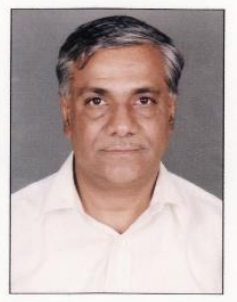

Prof.(Dr.) S. B. Wadkar

Professor , Mechanical Engineering Department, Sinhgad College of Engineering ,Pune 